\title{
FINANSIJSKO MODELIRANJE TROŠKOVA SREDSTAVA NAORUŽANJA I VOJNE OPREME
}

\begin{abstract}
Rezime
U uslovima restriktivnog budžetskog finansiranja odbrane efikasno i efektivno korišćenje novčanih sredstava više nego ikada postaje suštinsko pitanje funkcionisanja Ministarstva odbrane i Vojske Srbije (MO i VS). Svako ulaganje u akviziciju sredstava naoružanja i vojne opreme (NVO) usled finansijske značajnosti ne dopušta greške u odlukama.

Kvalitetno sagledavanje troškova sredstava kroz čitav programirani životni ciklus jeste složen multidisciplinaran i višekriterijumski problem čije rešavanje zahteva timsko angažovanje stručnjaka različitih profila. U našoj dosadašnjoj operativnoj praksi pri rešavanju navedenih problema nije bilo u dovoljnoj meri timskog rada navedenih eksperata pa su izostali i optimalni rezultati zasnovani na sinergiji. $U$ radu je analiziran investicioni proces opremanja sredstvima NVO u MO i VS, sa aspekta tretiranja troškova u tom procesu, ukazano je na njegove nedostatke i predložen sveobuhvatniji - integralni pristup ovom problem.

Ključne reči: investicije, opremanje, naoružanje i vojna oprema, troškovi.
\end{abstract}

\section{UVOD}

Ograničenost i strogo normativna definisanost su osnovne odlike budžetskog sistema Republike Srbije. Ova definisanost u većini slučajeva ima pozitivan uticaj na budžetski sektor kada se govori o namenskom trošenju i budžetskoj disciplini, ali i negativan kada se posmatra postignuće organa državnog aparata. $U$ ovom radu ćemo se fokusirati na deo postignuća organa odbrane koji se bave nabavkama i njihove problemske sadržaje u domenu obezbeđenja potrebnih sredstava naoružanja i vojne opreme za potreban nivo efikasnosti vojske. Sistem odbrane Republike Srbije funkcioniše u nestabilnim, dinamičnim i ekonomski veoma restriktivnim uslovima. Uprkos tome, zahtevi za dostizanjem odgovarajućih sposobnosti oružanih snaga sve su kompleksniji i sve izraženiji. Ispunjenje ovih zahteva podrazumeva, između ostalog, opremljenost oružanih snaga savremenim sredstvima naoružanja i vojne opreme (skraćeno NVO). Istovremeno, budžetska izdvajanja za ovu svrhu imaju trend permanentnog pada.

Za uspešno funkcionisanje u prisustvu ovako suprotstavljenih zahteva neophodno je postojanje dugoročnog koncepta razvoja sa ugrađenim organizacionim aspektom i savremeni menadžerski pristup u upravljanju resursima, odnosno menadžerski pristup orijentisan ka sprovođenju realnih i održivih strategija razvoja. On počiva na sveobuhvatnoj analizi problema, pronicljivom predviđanju budućih uslova funkcionisanja i dugoročno orijentisanom planiranju. $\mathrm{Na}$ taj način sprečava se odstupanje od proklamovanih ciljeva usled promene opcije na vlasti i napuštanje projekata i rešenja u koja su uložena sredstva velikog obima.

Svako značajnije ulaganje $u$ opremanje oružanih snaga naoružanjem i vojnom opremom predstavlja investiciono ulaganje koje po mnogim aspektima prelazi domen i mogućnosti MO i VS. Usled toga, prisustvo i neposredna uključenost države u ovom procesu su nezaobilazni. Optimizacijom utroška finansijskih sredstava i resursa svih vrsta na nivou države, uz dobru koordinirajuću ulogu vlade, isključuje se „feudalizacija“ u okviru direktnog korisnika budžetskih sredstava ili u okviru jedne organizacione celine direktnog korisnika budžetskih sredstava25. Vojna organizacija veoma pažljivo mora da upravlja raspoloživim kapitalom. $S$ toga je razumljivo pitanje opravdanosti svakog investicionog ulaganja u opremanje MO i VS sredstvima NVO.

Usled angažovanja obimnih finansijskih sredstava, prisustva rizika u pogledu konačnog ishoda i dugoročnih konsekvenci na funkcionisanje vojne organizacije nepobitna je neophodnost upravljanja investiranjem, zbog čega je proces opremanja MO i VS sredstvima NVO normativno regulisan.

Reforma javnog sektora koja se sprovodi u našoj zemlji obuhvata sve oblasti uključujući i odbranu, a u okviru iste poseban značaj se pridaje optimizaciji troškova, svih vrsta.

\footnotetext{
${ }^{23}$ Vojna akademija, Beograd

${ }^{24}$ Beogradska poslovna škola

${ }_{25}$ Parcijalne optimizacije (optimizacije na nivou podsistema) ne daju znatniji doprinos dostizanju proklamovanih ciljeva sistema u celini ukoliko ne prate ciljeve celog sistema i ukoliko nisu objedinjene jedinstvenom metodologijom rada.
} 
Cilj ovog rada jeste primena novog koncepta investiranja u NVO radi unapređenja postojećeg stanja u ovoj oblasti.

\section{PROCES OPREMANJA SISTEMA ODBRANE REPUBLIKE SRBIJE SREDSTVIMA NVO}

Tranzicijom privrede u Republici Srbiji veći deo javnog sektora, koji je mogao samostalno da funkcioniše transformisan je u skladu sa novim pravnim formama organizacije u privredna društva. Tako su i najveća preduzeća, koja se bave proizvodnjom naoružanja i vojne opreme organizovana kao privredna društva sa državnim vlasništvom kao, u većini slučajeva, većinskim akcionarom (manjinski vlasnik je u preduzeću "Trajal korporacija" iz Kruševca). Izlaženjem iz sistema javnog sektora, uvođenjem finansijske discipline kroz budžet i budžetski sistem, uvođenjem procedura javnih nabavki i dela poverljivih nabavki koje izlaze iz domena javnih uključivanjem platnog prometa u sistem Trezora, devizno plaćanje preko Narodne banke, uvođenjem izmena u sistemu prinudne naplate itd. obezbeđenje naoružanja i vojne opreme iz dela razvoja i serijske proizvodnje u većem delu je usporen, da ne kažemo i onemogućen.

Ovo normativno okruženje uticalo je na pojavu većeg uvoza, jer je vreme (skup često i neprocenjivo skup faktor), samo jedan primer da navedemo /ograničenje budžetske godine utiče na potrebu da se budžetska sredstva utroše do kraja budžetsko perioda 31.12./ usled nemogućnosti utroška sredstava zbog dužeg vremena proizvodnje pribegava se kupovini gotovog proizvoda sa tržišta koji je mnogo lakše i brše kupiti, naravno uključujući poštovanje budžetskog perioda.

Zbog niza društvenih promena i organizacionih promena u sistemu odbrane, u poslednje dve decenije, normativna regulativa, iz ovog domena nije u potpunosti usklađena zahtevima tržišta.

Regulisanjem imovine Republike Srbije i normativnim uspostavljanjem vertikalnih i horizontalnih odnosa izmeću subjekata državne uprave stvoren je ambijent u kome se opremanje sistema odbrane mora prilagoditi i normativno urediti. Osnovni dokument kojim su regulisani organizacija, nadležnosti, kriterijumi i postupci pri opremanju MO i VS sredstvima NVO u miru jeste Pravilnik o opremanju Vojske Jugoslavije naoružanjem i vojnom opremom u miru (Pravilnik) iz 1966. godine.

Od ostalih normativnih dokumenata koji regulišu aktivnosti u domenu opremanja sredstvima NVO prisutno je više Standarda narodne odbrane, kao što su npr. SNO 0477/83, SNO 1096/85, SNO 8196/92, SNO 9000/97 i dr. Navedeni standardi tretiraju pojedine aspekte ili aktivnosti tokom procesa opremanja sredstvima NVO.

Za sve vrste sredstava NVO određeni su taktički i tehnički nosioci i nosioci planiranja (organi nadležni za razvoj i istraživanje, definisanje sistema održavanja, nabavku i dr.). Ministarstvo odbrane i VS se opremaju sredstvima NVO kroz procese planiranja, programiranja, istraživanja, razvoja, proizvodnje, ispitivanja i nabavke ${ }^{26}$. U skladu sa tim, opremanje MO i VS sredstvima NVO vrši se po jednom od sledećih modela:

- istraživanjem i sopstvenim razvojem,

- osvajanjem po licencnoj dokumentaciji ili razvojem kopiranjem po uzorku,

- razvojem u kooperaciji sa inostranim partnerom,

- nabavkom gotovih sredstava iz uvoza,

- nabavkom sa domaćeg tržišta gotovih proizvoda,

- prijemom donacija i

- kombinovanim modelom opremanja.

Analizom aktivnosti u procesu opremanja sredstvima NVO, možemo izdvojiti sledeće elemente: taktička studija, prethodna analiza i program realizacije kao osnovna polazna dokumenta u procesu. Pri tome, taktička studija nije obavezna u svim modelima opremanja sredstvima NVO. Takođe, prema definisanim sadržajima, prethodne analize i programa realizacije uočljiv je akcenat na tehničko tehnološkom aspektu analize opremanja, dok je ekonomski aspekt (aspekt troškova prvenstveno) prisutan, ali ne i detaljnije apsolviran.

U sadržaju prethodne analize jedan segment treba da bude projekcija troškova razvoja, proizvodnje, opremanja, integralnog tehničkog obezbeđenja, cene sredstva, puta realizacije, uslova razvoja i investicija sa rokovima izvršenja, ali nije ukazano na potrebu sagledavanja ukupnih troškova tokom životnog veka sredstva ${ }^{27}$.

U sadržaju programa realizacije, u tehno - ekonomskoj analizi, troškovi su sistematizovani, ali još uvek bez dovoljno direktnih smernica o načinu i vremenskom aspektu njihovog obračuna.

\footnotetext{
${ }^{26}$ Pravilnik o opremanju Vojske Jugoslavije naoružanjem i vojnom opremom u miru, Savezno ministarstvo za odbranu, Službeni vojni list 25/1996, Beograd, 1996.

27 Sopstveni razvoj TMS (radi opremanja) preduzima se na osnovu odluke nadležnih organa, a životni ciklus sredstva u ovom slučaju obuhvata sledeće faze: prethodnu analizu, taktičku studiju, program realizacije, razvoj SRT po usvojenom programu realizacije, ispitivanje prototipa - probne partije, odluka o usvajanju SRT u naoružanje i opremu, izradu nulte serije, ispitivanje nulte serije, rešenje o prijemu nulte serije, serijsku proizvodnju, praćenje i izveštavanje o ponašanju u toku eksploatacije, otuđenje (rashodovanje, uništenje,...).
} 
Analizom slučajeva u MO i VS, uočen je različit pristup tretiranju troškova prilikom investiranja u opremanje sredstvima NVO. U najboljem slučaju prisutan je samo statički pristup analizi i oceni investicionih projekata, dok se dinamčki aspekt i aspekt ukupnih troškova tokom celog životnog veka sredstava ne uzimaju u obzir.

Naime, prihvatanje određenog investicionog projekta zavisi od stepena zadovoljenja zahteva koji se pred taj projekat stavljaju, a koji se uglavnom odnose na maksimiziranje odnosa između efekata i ulaganja. Shodno primenjenim kriterijumima i odgovarajućim ulaznim parametrima, sve ocene investicionih projekata mogu biti statičke ili dinamičke ${ }^{28}$. Pri tome, statički pristup oceni projekata je karakterističan za predinvesticione studije, odnosno za "male” i "srednje” projekte, dok je dinamičkki pristup zastupljen u investicionim studijama "malih" i „srednjih” projekata, ali i u predinvesticionim studijama „velikih" projekata. Po svojoj prirodi, opremanje MO i VS sredstvima NVO uglavnom predstavlja „velike" projekte.

Evidentno je da donošenju investicione odluke o opremanju sredstvima NVO prethodi veliki broj istraživačko - razvojnih aktivnosti. Normativnom regulativom i prisutnom organizacionom praksom ne tretira se materijalno - finansijski aspekt u skladu sa njegovim značajem, pa se investicione odluke često donose na bazi intuicije i empirije, što samo povećava rizik u ostvarenju projektovanih ciljeva. Neadekvatno sagledavanje troškova investiranja u opremanje sredstvima NVO, u predinvesticionom periodu, često dovodi do stvaranja privida i onemogućava potpuno pravilno sagledavanje i ocenu opravdanosti investiranja. Usled toga, tokom perioda eksploatacije sredstva, sve do njegovog "odlaska" iz sistema pojavljuju se ogromni troškovi koji nisu bili predviđeni, a time ni planirani. Uticaj ovih troškova dovodi u pitanje upotrebljivost sredstava, svrsishodnost i naročito opravdanost investiranja.

\section{TROŠKOVI UPOTREBE SREDSTAVA NVO U SISTEMU ODBRANE REPUBLIKE SRBIJE}

Ograničeni finansijski resursi za potrebe odbrane, stalno rastući troškovi pribavljanja, eksploatacije i podrške sistema NVO, stvorili su potrebu da troškovi postanu jedan od glavnih parametara pri opremanju vojske, odnosno da se proces upravljanja troškovima postavi na mesto koje zauzima i u razvijenim zemljama. Investiranje u pribavljanje opreme iziskuje da se sistematizovano sagledavaju troškovi eksploatacije i podrške u troškovima životnog ciklusa.

Finansijskom analizom troškova životnog ciklusa neophodno je primeniti adekvatnu metodologiju. Prilikom analize troškova u životnom ciklusu NVO mogu se uočiti dve grupe troškova, direktni i indirektni troškovi. Direktni troškovi, prepoznaju se od strane taktičkih nosilaca (planskih organa) ${ }^{29}$ i najčešće obuhvataju troškove pribavljanja sredstava. Indirektni troškovi su višeg iznosa i obuhvataju nekoliko grupa troškova, koje najčešće ne obuhvataju planeri. U indirektne troškova se ubrajaju: pogonski troškovi, troškovi održavanja, troškovi obuke, troškovi zaliha, troškovi informacionog sistema, troškovi otuđenja i rashodovanja itd.

$\mathrm{U}$ toku upravljanja projektom usvajanja sredstava ratne tehnike u NVO Vojske moraju uzeti u obzir svi napred navedeni troškovi. Pri razmatranju istih treba identifikovati više alternativnih rešenja (potencijalnih izbora) koja ispunjavaju određene kriterijume, sa težnjom da ista daju optimalne kombinacije.

Problem koji se pri tome rešava je višekriterijumske prirode ${ }^{30}$, bilo da se radi o optimalnoj kombinaciji troškova kod jednog tehničkog sistema (sredstva NVO) ili da se radi o izboru jednog sistema NVO između više mogućih - ponuđenih. Za rešavanje navedenih problema mogu se koristiti brojne metode i tehnike, različite snage i generalnosti.

Primarni zadatak se sastoji u izboru koncepcije upravljanja, orijentisane ka sredstvu, tako da u toku rada isto zadovolji operativne zahteve uz najniže troškove životnog ciklusa.

Analizom troškova ${ }^{31}$ moguće je identifikovati sledeće glavne grupe troškova, u životnom ciklusu sredstva:

- pribavljanja

- troškove eksploatacije i podrške i

\footnotetext{
${ }^{28}$ Jovanović, P., Upravljanje investicijama, Grafoslog, Beograd, 2002.

${ }^{29}$ Pod taktičkim nosiocima se podrazumevaju organi u sistemu odbrane koji su odgovorni za istraživanje, razvoj, usavršavanje i usvajanje materijalnih sredstava iz svoje nadležnosti, snabdevenost jedinica i ustanova svoga vida, roda i službe tim materijalnim sredstvima, praćenje ponašanja TMS u eksploataciji i poboljšanje taktičko-tehničkih karakteristika.

${ }^{30}$ Svaki kriterijum može imati više potkriterijuma koji različito utiču na vrednost kriterijuma, sa aspekta krajnjeg cilja.

${ }^{31}$ Analiza troškova životnog veka može da se definiše kao sistematski analitički proces ocene različitih alternativnih pravaca akcije u cilju izbora najboljeg puta za korišćenje ograničenih sredstava. Koristi se za ocenu alternativnih: konfiguracija sistema i njihovog projektovanja, proizvodnih šema, koncepcija održavanja i sl.

Analiza se vrši korak po korak, koristeći procenu troškova životnog veka kao kriterijum za dobijanje najpogodnijeg rešenja problema u odnosu na troškove. Proces analize je u suštini iterativan i može da se primeni na bilo koju fazu životnog veka sistema/sredstva.

U toku životnog veka sistema/sredstva zahtevaju se mnoge odluke tehničke i ne tehničke prirode. Većina tih odluka, posebno onih koje se donose u ranijim fazama programa, imaju veliki uticaj na troškove životnog veka. Pri tome, treba u što većoj meri sagledati sve probleme koji, bilo direktno, bilo indirektno, utiču na troškove životnog veka.
} 
- troškove otuđivanja.

Prva grupa troškova događa se samo jednom u toku životnog ciklusa sredstva. Ostale grupe troškova se ponavljaju tokom niza godina dok je sredstvo u upotrebi.

Troškove eksploatacije sačinjavaju troškovi koje generišu resursi koji su potrebni za eksploataciju i pružanje svih oblika podrške sistemu, podsistemu ili nekom glavnom sastavnom delu tokom njegovog veka trajanja u eksploatacionom periodu. Ovde se ubrajaju i troškovi nabavke i čuvanje energenata (municije, goriva, energetskih izvora...).

Troškovi otuđivanja se u slučajevima gde su promenljivi moraju razmatrati posebno, a obuhvataju i troškove nabavke istih sredstava radi zamene dotrajalih ili uništenih. $U$ drugim situacijama se ne izdvajaju posebno, nego se razmatraju u okviru troškova eksploatacije i podrške.

Procene troškova moraju razmatrati efekte inflacije, pada vrednosti valute, kredita i druge faktore koji prouzrokuju promene u troškovima. Ocene troškova se izvode iz kombinacije istorijskih podataka, projekcija troškova projekata, predloga izvršilaca i prognozom uz primenu kvantitativnih i kvalitativnih metoda.

U toku razvoja metodologije proračuna svih troškova sredstva u toku životnog veka najpre je potrebno identifikovati i razdvojiti pojedine grupe troškova. Prilikom analize svih grupa troškova potrebno je izvršiti i raspodelu troškova prema dinamici utrošaka sredstava u zavisnosti od izabranog modela opremanja.

Početni, direktni, troškovi ili troškovi pribavljanja, prikazuju početna ulaganja prilikom razvoja sredstva ili kupovine ali iskustveno se pokazalo da početna cena ne može biti presudna u donošenju odluke o izboru sredstva sa aspekte troškova u životnom veku sredstva. Prilikom analize troškova pribavljanja potrebno je sagledati:

- cenu sredstva sa pratećom opremom,

- početnu cenu logističke podrške,

- troškove rizika nabavke,

- troškove programa realizacije nabavke sredstava,

- troškove ispitivanja sredstava radi nabavke,

- troškove finansiranja,

- troškove rizika,

- troškove nabavke i distribucije sredstava.

\section{PRILOG OPTIMIZACIJI UTROŠKA FINANSIJSKIH SREDSTAVA U PROCESU NABAVKE SREDSTAVA NVO}

Da bi obezbedili što povoljniji investicioni tretman pri odlučivanju neophodno je preduzeti adekvatne strateške, operativne i administrativne aktivnosti. Strateške aktivnosti, za sistem odbrane, su: planiranje i razvijanje organizacije i infrastrukture nabavke, ciljno određivanje najbolje upotrebe stručnosti i sredstava nabavki, identifikovanje standarda delovanja koje treba postići, uspostavljanje kontrole i mehanizma izveštavanja.

Operativne aktivnosti predstavljaju: zahtevne specifikacije, ispitivanje opcija istraživanja snabdevanja robama ili uslugama, procena ponuda i dobavljača, pregovaranje, vođenje ugovora i projekata.

Administrativne aktivnosti obuhvataju: obrada i otpremanje narudžbenice, upoređivanje potvrda o isporuci/prijemu, prijem i provera faktura, vođenje zapisnika.

Uspostavljanje efikasnog i zakonitog sistema nabavki u MO i VS podrazumeva dobro poznavanje i poštovanje zakona i pratećih propisa, odgovarajuće organizaciono pozicioniranje službe za nabavke u okviru sistema odbrane, normativno uređenje postupaka, adekvatan izbor i permanentna edukacija kadrova, dobru obučenost i poštovanje standarda etičkog ponašanja od strane službenika zaduženih za poslove nabavki.

Rukovodioci organizacionih celina u MO i VS, službenici koji su direktno uključeni u proces nabavki i sva ostala lica koja su u poziciji da, u bilo kojoj meri i na bilo koji način, utiču na postupak odlučivanja o izboru ponuđača, dužni su da što bolje upoznaju sistem nabavki i da svoje obaveze ispunjavaju dosledno, korektno i stručno. Da bi se to postiglo, potrebno je jasno definisati aktivnosti, nosioce, obaveze i odgovornosti svih lica uključenih u postupak nabavke, koja će dobiti jasne i, kad god je moguće, pisane instrukcije o radu.

Potencijalni propusti koji se javljaju kod nabavki sredstava NVO, a koji utiču na optimizaciju utroška finansijskih sredstava, se odnose na sledeće: nedostatak adekvatnog kadra; neprecizno normativno uređenje nabavki; nepostojanje višegodišnjih okvirnih ugovora vezanih za nabavke; nedovoljno i neadekvatno istraživanje tržišta; nepotpuno pridržavanje postojeće normative; kasno stavljanje novčanih sredstava na raspolaganje službi nabavke; nepravovremeno i neprecizno planiranje nabavki; nekvalitetna tehnička dokumentacija; nepoštovanje rokova, neadekvatna frekfencija nabavki; 
veći broj „hitnih i poverljivih nabavki; nepostoji sistemsko limitiranje vremena rada ljudstva na poslovima nabavki; odsustvo adekvatne strukture koja bi se bavila poslovima kontrole u oblasti nabavki" idr..

Veliki deo troškova bio bi procenjen sa velikom verovatnoćom uvođenjem jedinstvenog informacionog sistema [12], tj. formiranjem baze podataka koja bi, ako ne danas, sigurno omogućila budućim generacijama rešavanje problema I pravilnu procenu ekonomičnosti sredstava prilikom opremanja vojske NVO.

\section{ZAKLJUČAK}

Investicioni segmentirani pristup troškovima prilikom razvoja i proizvodnje sredstva NVO iziskuje obezbeđenje adekvatne logističke podrške. Za bolju kontrolu troškova treba uložiti više napora u analizi integralne logističke podrške (ILP) i ukupnih troškova životnog veka sredstva NVO.

Koncept ILP zahteva povezivanje operativne gotovosti sa troškovima životnog veka.

Ukupni troškovi eksploatacije $\mathrm{i}$ održavanja prvenstveno zavise od cene radnog časa $\mathrm{i}$ cene delova koji se ugrađuju, dok su ostali troškovi manje uticajni na ukupne troškove životnog veka sredstva.

Svrsishodno je da se investira u početnim fazama preko povećanja pouzdanosti i pogodnosti za rukovanje i održavanje da bi se dobilo sredstvo sa većom efikasnošću, uz niže troškove životnog veka.

Prilikom proračuna troškova pojedini podaci mogu se dobiti direktno od proizvođača mada treba uvek imati u vidu da prodavac uvek želi da proda svoj proizvod. Određeni podaci pronalaze se u bazama podataka o sredstvima koja su korišćena u prethodnom periodu, te je zbog toga neophodno prilikom opremanja paralelno formirati i odgovarajuću bazu podataka koja će biti dokumentaciona podloga u budućnosti.

Kritične informacije, kao što su pouzdanost ili srednje vreme između otkaza delova, sklopova i agregata najčešće se mogu naći kod partnera koji već koriste identična sredstva ili na neki drugi način, $s$ obzirom da proizvođači takve informacije najčešće daju tek nakon sklapanja ugovora.

$S$ obzirom da opremanje vojske naoružanjem i vojnom opremom polazi od strategijskih opredeljenja države, treba imati u vidu da se sredstva nabavljaju za period od oko 30 godina i da u tom periodu moraju biti što efikasnija sa mogućnošću da odgovore operativnim zahtevima u predviđenim uslovima upotrebe. To znači da i ako u određenom periodu veka upotrebe određeno sredstvo ne omogućava efikasnosnu upotrebu potrebno je predvideti mogućnost i troškove eventualne modernizacije ili adaptacije.

Najveći troškovi ispoljavaju se u funkcionalnoj nadležnosti logistike što govori da opremanje vojske mora biti zasnovano na logističkim principima i održivosti, jer se tako ostvaruju znatne uštede u čitavom životnom ciklusu sredstva.

Radi kvalitetnog sagledavanja ukupnih troškova neophodno je razviti, standardizovati i sistemski uvesti u operativnu primenu adekvatnu metodologiju proračunavanja troškova i adekvatan informacioni sistem. Uloga informacionih i komunikacionih sistema je veoma bitna kod svih organizacionih promena. Informacioni i komunikacioni sistemi imaju naročit značaj u slamanju otpora promenama i sprečavanju održavanja trenutnog stanja.

Integrisani pristup proračuna i smanjenja troškova životnog veka sredstava NVO treba da prati opšte trendove u reformi javnog (državnog) sektora, optimizacija troškova i efikasnosti, timski pristup rešavanju složenih problema; veća transparentnost; kraće vreme odziva; uvođenje radno-stimulativnog sistema, smanjenje režijske radne snage, javno-privatna pertnerstva, multinacionalne projekte, a sve sa ciljem da se uz manji utrošak resursa pruži bolje rešenje, proizvod ili usluga odnosno viši stepen zadovoljenja javnog (državnog) interesa. U oblasti odbrane to znači održiva i pametna odbrana i multinacionalni pristup u realizaciji skupih projekata.

U cilju optimizacije troškova životnog ciklusa sredstava neophodno je, na svim nivoima studija i usavršavanja ljudstva, izučavati određene sadržaje ILP, primenjivati adekvatan koncept i pristup i predviđati i pratiti organizaciono-tehnološke promene u sistemu odbrane.

\section{LITERATURA}

1. Todorović, J., Đuričin, D., Janošević, S., Strategijski menadžment, Institut za tržišna istraživanja, Beograd, 2000.

2. Jovanović, P., Upravljanje investicijama, Grafoslog, Beograd, 2002.

3. Pravilnik o opremanju Vojske Jugoslavije naoružanjem i vojnom opremom u miru, Savezno ministarstvo za odbranu, Službeni vojni list 25/1996, Beograd, 1996.

4. Andrejić, M., Radosavljević, V., Arsić, S. Logističko obrazovanje i obučavanje nelogističkog osoblja, Vojnotehnički glasnik/Military Technical Courier, Vol. 59, No. 1, pp.5-26, ISSN 00428469, UDC 623+355/359, Ministarstvo odbrane Republike Srbije, Beograd, 2011. 
5. Andrejić, M., Milenkov, M., Sokolović, V. Logistički informacioni sistem, Vojnotehnički glasnik/Military Technical Courier, Vol. 58, No. 1, pp.33-61, ISSN 0042-8469, UDC 623+355/359, Ministarstvo odbrane Republike Srbije, Beograd, 2010.

\section{Abstract}

In terms of restrictive budget financing of Defence efficient and effective use of funds more than ever becomes an essential question the functioning of the Ministry of Defense and the Army of Serbia (MoD and SAF). Any investment in the acquisition of armaments and military equipment (AME) due to the financial significance does not allow mistakes in the decisions.

Quality assessment of the cost of funds through lifecycle is a complex multidisciplinary and multicriteria problem whose resolution requires the engagement of a team of professionals of different profiles. In our previous operational practices in solving these problems has not been sufficiently teamwork mentioned experts and were left behind and optimal results based on synergy. This paper analyzes the investment process of equipping armament in the MoD and SAF in terms of treatment costs in the process, pointed out its shortcomings and suggested more comprehensive - integral approach to this problem.

Key words: investment, equipment, weapons and military equipment, costs. 